\title{
Assessment of the nutritional knowledge of undergraduate pharmacy students: The need to advance nutrition education in the training of pharmacy students
}

\author{
Juman Abdulelah Dujaili 1 (D) , Ali Blebil ${ }^{1}$ (D) , David Chong 2 (iD) \\ ${ }^{1}$ School of Pharmacy, Monash University Malaysia, Bandar Sunway, Malaysia \\ 2 Department of Pharmacy Practice, International Medical University, Kuala Lumpur, Malaysia
}

\author{
Keywords \\ Education \\ Formative assessment \\ Knowledge \\ Nutrition \\ Pharmacy students
}

\author{
Correspondence \\ Juman Abdulelah Dujaili \\ School of Pharmacy \\ Monash University Malaysia \\ Jalan Lagoon Selatan \\ Bandar Sunway \\ 47500 Subang Jaya \\ Selangor \\ jumandujaili@yahoo.com
}

\begin{abstract}
Objective: This study aimed to assess pharmacy students' knowledge of aspects of nutrition relevant to pharmacy practice and as a means of imparting information through feedback to support learning and professional development. Method: 230 pharmacy students completed a 30-item nutritional informal assessment questionnaire, along with confidence assessment questions. Students were asked about the sources of information they used to answer the knowledge assessment questions, their learning experience with regards to nutrition, and their inclination to learn more about nutrition. Results: Generally, Year four pharmacy students had significantly higher scores than Year two students. However, their overall performance was still lower than that expected of graduate pharmacists. About $75.0 \%$ of the study participants agreed that they would like to learn more about nutrition. Conclusion: This study indicates the need to integrate better nutritional education into the undergraduate pharmacy curriculum. The results also suggest a need for Malaysian schools of pharmacy to offer focused learning on nutrition aligned with national health priorities and the competency level in relation to nutrition of pharmacy graduates in the country.
\end{abstract}

\section{Introduction}

Pharmacists, especially community pharmacists, have enormous potential to aid public health literacy about nutrition. They not only see members of the general public who are receiving medication, but also those who are healthy and those who could be considered at risk through poor nutrition (Macdiarmid, Gatenby, \& Mason, 1993). In order to improve public knowledge of nutrition, however, pharmacists must be equipped with the essential knowledge and skills on this topic. Despite the demand for a primary care nutrition focus unit, few pharmacy schools have integrated nutrition education into their undergraduate curriculum (Chang et al., 2008; Pearce, \& Cross, 2013; Pogge, 2013). The importance of including nutrition in the teaching and learning of pharmacy students and the continuing training of practising pharmacists remains a low priority; The lack of required primary nutrition training within pharmacy and other healthcare curricula; and the absence of curricular coordination between health professions, demonstrates this problem. This study aimed to compare the nutritional knowledge of pharmacy students to gauge their progress in pharmacy professional education. The study evaluates the current pedagogic models and highlights the imperative need to realign and synergise these models to reflect evidence-based and outcomes-focused education. 


\section{Methods}

\section{A Study design \& study participants}

A cross-sectional study was conducted at International Medical University (IMU), Malaysia, to assess Year four and Year two pharmacy students' knowledge of primary care nutrition. Year two students were selected as they had received formal didactic lectures, workshops and professional skills development sessions on cardiovascular, renal, and respiratory systems and would be expected to be able to answer the questions. Upon completion of the questionnaire, students were sent the link to the answers and further explanations.

Students were informed about the study, in which they could voluntarily participate with guaranteed confidentiality. Before analyses, all data was coded and saved without directly identifiable information. Furthermore, the study was approved by Joint Committee of Research and Ethics at IMU.

\section{Knowledge assessment test development}

The questionnaire was designed for formative assessment by evaluating students' knowledge of basic nutrition principles and their ability to apply this knowledge to practical advice. Besides, it was designed for teaching purpose by providing feedback to impart information on the areas covered. The steps of the knowledge assessment test include:

1) curriculum review to identify the nutrition content covered within the curriculum,

2) item pool generation in which three pharmacy practice educators were involved,

3) item selection,

4) vetting process,

5) pilot testing among a sample of Year three students who were not involved in the actual study, and

6) refinement and finalisation

The test comprised 30 single best answer multiple-choice items. The topic areas tested include:

1) essential nutritional concepts,

2) essential dietary treatment of type 2 diabetes mellitus,

3) essential dietary interventions in common chronic gastro-intestinal, renal and cardiovascular conditions, and

4) nutrition for healthy pregnancy and breastfeeding

\section{Procedure}

A written information sheet described the purpose of the study and provided an opportunity for the student to accept or decline participation. Participants were then asked to complete a two-part study set. Part 1 consisted of 30 single best answer multiple-choice items aimed at assessing nutritional knowledge, with confidence assessment. All confidence assessment items were rated on a 3-point Likert scale where 1 = non-confident, 2 = not sure, and 3 = confident. Students would only receive a score if they answered the knowledge item correctly and rated themselves as confident. Part 2 consisted of multiple-choice items assessing their learning experience about nutrition, their inclination to learn more about nutrition as future pharmacists, and the sources of information used to answer the knowledge assessment questions.

\section{Statistical analyses}

Student answers were coded and analysed using Statistical Package for Social Sciences (SPSS) 22 software. Descriptive statistics were carried out using frequencies for categorical variables and mean \pm SD for continuous variables. Moreover, an independent-samples t-test and MannWhitney U Test were used to compare pharmacy students' nutritional knowledge mean score.

\section{Results}

230 subjects were included in the study; 100 and 130 students from final and second year, respectively. The description of the questionnaire used to assess the nutritional knowledge of pharmacy students is presented in Table I and Table II. The questionnaire comprises six sections. The scores range from 0 to 30 . In this aspect, only students who were correct and confident were scored 1 for each item. The answer would be considered incorrect (i.e. score 0) if the respondent indicated that they were non-confident or when the answer was wrong.

A comparison was made between Year four and Year two students in terms of the total scores. There was a significant difference in the student's total score (5.98 \pm 2.55 vs. $4.26 \pm 2.43$, for Year four and two respectively), Mann-Whitney $U$ value $=9088.5, z=5.215$ ( $z$ denotes the standardised Test Statistic), $p<0.001$, and $r=0.34$ (where $r$ represents the effect size). Moreover, the results demonstrate no significant difference between Year four and Year two pharmacy students in terms of the essential nutrition concept. 
Table I: Description of nutritional knowledge questionnaire

\begin{tabular}{|c|c|c|c|c|}
\hline \multirow[t]{2}{*}{ Topic covered } & \multirow{2}{*}{$\begin{array}{l}\text { Number of } \\
\text { questions }\end{array}$} & \multicolumn{2}{|c|}{ Range of scores } & \multirow{2}{*}{$\begin{array}{l}\text { Mean } \quad \pm \\
\text { Standard } \\
\text { Deviation }\end{array}$} \\
\hline & & Expected & Observed & \\
\hline $\begin{array}{l}\text { Essential Nutrition } \\
\text { Concept }\end{array}$ & 3 & $0-3$ & $0-2$ & $0.90 \pm 0.70$ \\
\hline $\begin{array}{l}\text { Cardiovascular } \\
\text { Disease }\end{array}$ & 7 & $0-7$ & $0-3$ & $1.10 \pm 0.98$ \\
\hline Renal Disease & 6 & $0-6$ & $0-4$ & $0.98 \pm 0.96$ \\
\hline Women's Health & 5 & $0-5$ & $0-4$ & $0.87 \pm 0.86$ \\
\hline Diabetes mellitus & 6 & $0-6$ & $0-4$ & $0.57 \pm 0.82$ \\
\hline $\begin{array}{l}\text { Gastrointestinal } \\
\text { Disorders }\end{array}$ & 3 & $0-3$ & $0-3$ & $0.59 \pm 0.70$ \\
\hline Total questions & 30 & $0-30$ & $0-13$ & $5.01 \pm 2.62$ \\
\hline
\end{tabular}

Table II: Comparison between Year two and four pharmacy students in term of the total score for the topics on nutritional knowledge

\begin{tabular}{|c|c|c|c|c|c|c|}
\hline \multirow[t]{2}{*}{ Variable } & \multicolumn{2}{|c|}{ Mean \pm SD } & \multirow[t]{2}{*}{$U^{*}$} & \multirow[t]{2}{*}{$\mathrm{z}^{* *}$} & \multirow[t]{2}{*}{$r^{+}$} & \multirow[t]{2}{*}{$p$} \\
\hline & Year two & Year four & & & & \\
\hline $\begin{array}{l}\text { Essential } \\
\text { Nutrition } \\
\text { Concept }\end{array}$ & $0.94 \pm 0.73$ & $0.84 \pm 0.66$ & 6048.0 & -0.985 & 0.06 & 0.325 \\
\hline $\begin{array}{l}\text { Cardiovascular } \\
\text { Disease }\end{array}$ & $1.58 \pm 0.92$ & $0.49 \pm 0.67$ & 2453.0 & -8.470 & 0.56 & $<0.001$ \\
\hline Renal Disease & $0.54 \pm 0.85$ & $1.55 \pm 0.80$ & 10618.0 & 8.698 & 0.57 & $<0.001$ \\
\hline $\begin{array}{l}\text { Women's } \\
\text { Health }\end{array}$ & $0.69 \pm 0.83$ & $1.10 \pm 0.85$ & 8290.5 & 3.823 & 0.25 & $<0.001$ \\
\hline $\begin{array}{l}\text { Diabetes } \\
\text { Mellitus }\end{array}$ & $0.23 \pm 0.47$ & $1.01 \pm 0.96$ & 9664.5 & 7.237 & 0.47 & $<0.001$ \\
\hline $\begin{array}{l}\text { Gastro- } \\
\text { intestinal } \\
\text { Disease }\end{array}$ & $0.28 \pm 0.50$ & $0.99 \pm 0.70$ & 10001.5 & 7.795 & 0.51 & $<0.001$ \\
\hline $\begin{array}{l}\text { Student's } \\
\text { Total Score }\end{array}$ & $4.26 \pm 2.43$ & $5.98 \pm 2.55$ & 9088.5 & 5.215 & 0.34 & $<0.001$ \\
\hline 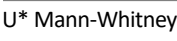 & yU value & & & & & \\
\hline
\end{tabular}

Students were also asked about their inclination to learn more about nutrition and whether they considered the knowledge that they have received within the pharmacy curriculum to be adequate. The majority of pharmacy students agreed that they needed to learn more about nutrition. Furthermore, students were asked about the source of their nutritional knowledge. Interestingly, the majority of the students indicated that online media is the main source, followed by the pharmacy curriculum. The results are presented in Table III and Table IV.
Table III: Pharmacy students preference and perception regarding nutrition education in pharmacy curriculum

\begin{tabular}{|c|c|c|c|}
\hline Variables & Agree & Neutral & Disagree \\
\hline $\begin{array}{l}\text { I would like to learn more about } \\
\text { nutrition }\end{array}$ & $172(74.8 \%)$ & $53(23.0 \%)$ & $5(2.2 \%)$ \\
\hline $\begin{array}{l}\text { The nutrition knowledge that I } \\
\text { have received currently as a part } \\
\text { of pharmacy programme is } \\
\text { adequate to provide effective } \\
\text { advice to the patient regarding } \\
\text { their diet modification }\end{array}$ & $31(13.5 \%)$ & 107 (46.5\%) & 92 (40.0\%) \\
\hline
\end{tabular}

Table IV: Students' source of nutrition information

\begin{tabular}{lll}
\hline Source of information & Responses & $\mathbf{N}(\%)$ \\
\hline Online resource & Yes & $155(67.4)$ \\
Pharmacy curriculum & No & $75(32.6)$ \\
& Yes & $116(50.4)$ \\
Academic literature & No & $114(49.6)$ \\
Personal communication & Yes & $77(33.5)$ \\
& No & $153(66.5)$ \\
Other sources used & Yes & $68(29.6)$ \\
& No & $162(70.4)$ \\
& Yes & $58(25.2)$ \\
& No & $172(74.8)$ \\
\hline
\end{tabular}

\section{Discussion}

Pharmacists are the most reachable and reliable healthcare professions and can play an essential role in disease prevention and health promotion using clinical nutritional interventions when educating patients in both clinical and community settings. However, to do so, they have to be equipped with the essential knowledge and skills (Chang et al., 2008).

To date, this is the first study in Malaysia to assess the knowledge of pharmacy students in terms of primary care nutrition. The results demonstrated that the current nutrition knowledge of Year two and four students was insufficient to obtain a minimum score of 15 out of 30 . The students were provided feedback as part of an informal lesson. Each of the questions was supplemented with evidence-based explanations on each answer option.

The findings showed that Year four students had higher scores in all subscales except for essential nutrition concepts and cardiovascular disease; however, the results were not statistically significant for the essential nutritional concept, which was not surprising. Students' critical evaluation skills improve through Year three during their experiential learning projects and are solidified during the fourth year when students are engaged in clinical advanced pharmacy practice experiences during their placement in 
hospital and community pharmacies. A cross-sectional study conducted among healthcare workers to assess their nutritional knowledge showed that there was a significant difference $(p<0.001)$ between different healthcare professions and medical practitioners, with the results showing that pharmacist scored the lowest (Munuo et al., 2016).

A study was conducted in the United Kingdom to assess nutritional knowledge and undergraduate training of community pharmacists (Macdiarmid et al., 1993). The result showed that the overall mean score on the nutrition section was $67.5 \%$ (range $35.0 \%-90.0 \%$ ). As a result of the survey, the pharmacists made comments suggesting concern about the inadequacy of their knowledge in nutrition as well as the inadequacy of undergraduate and post-qualification training in nutrition (Macdiarmid et al., 1993). Another study of nutrition content in pharmacy schools' curricula in the United Kingdom showed that nutrition teaching is limited. Only two schools indicated stand-alone units with regards to nutrition; elsewhere, the subject was incorporated into other units with an average time allocation of only two hours (Pearce, \& Cross, 2013).

Consistently, the presented results demonstrated that pharmacy students had a maximum score of 13 out of 30 . These findings emphasise the need to create, implement, and evaluate a nutrition course to improve students' knowledge of nutrition in pharmacy practice. In a 2010 American Association of Colleges of Pharmacy (AACP) report to address unmet patient care needs and pharmacists' contribution, the committee discussed the role of pharmacy educators and academic administrators in determining the core elements of education and training to fill the knowledge gaps for pharmacists to serve as primary care professionals (Manolakis, \& Skelton, 2010). This reaffirms the need for the inclusion of nutritional courses for pharmacy students.

Furthermore, students were asked whether they would like to learn more about nutrition. The majority of students in the cohort agreed to learn more about nutritional intervention to prevent and treat diseases. These findings are consistent with the results of other studies (Kris-Etherton et al., 2014; Makowske, \& Feinman, 2005; Munuo et al., 2016). A team-based learning course on nutrition and lifestyle modification for pharmacy students were carried out at Midwestern University College of Pharmacy-Glendale, Glendale, United States of America. Students were satisfied with the concept of team-based learning, and their knowledge of nutrition and lifestyle modification improved significantly (Pogge, 2013).
The questionnaire consisted of items assessing student learning experience regarding the adequacy of the pharmacy curriculum to provide effective advice to patients about diet modification and their inclination to learn more about nutrition. The majority of the students in our cohort were neutral, and around $75.0 \%$ agreed that they need to receive extra teaching about nutrition. Moreover, $67.4 \%$ of students used online resources as a source of information and learning for their nutrition knowledge. Although pharmacy students have easy access to an extensive range of quality learning resources, many may refer to resources shared through social media. Students routinely turn and are directed toward online information sources and services (Cook et al., 2008; O'Carroll et al., 2015). Unit-related learning activities are better supported by resources delivered through university learning platforms (Judd, \& Elliott, 2017). A recent study has shown that some online information had knowledge deficiencies, were inaccurate and unsuitable learning resources for students (Azer, 2015).

\section{Limitations}

There were a few limitations in this study. First, single best answer multiple-choice items were used to assess knowledge, which may not accurately reflect the actual knowledge for all students. Secondly, the knowledge retention aspect of the nutritional concepts covered. It is worth assessing knowledge retention over a long period. It remains to be established whether knowledge retention continues to decrease with time or the baseline level of knowledge is retained, leading to a plateau of knowledge retention (Valdez et al., 2006). Lastly, this test was not considered to be 'high stakes' in that it did not count towards or against student grades, and therefore, some students may not have been motivated to answer questions to the best of their ability. Furthermore, students who experienced difficulty answering multiplechoice questions may possess more excellent knowledge than that reflected in the knowledge score

\section{Conclusion}

Improving the delivery of nutrition care in different settings, including hospital and retail environments, is essential to improving population health, to counter the challenges of obesity, lifestyle and ageing to health and healthcare costs. There is an urgent need to better prepare pharmacists to address nutrition-related 
conditions using good validated practice. A multidisciplinary educational initiative is required to develop nutrition education competencies and curricula for pharmacy, which are informed by good practice and patients outcomes. Inclusion of nutrition in pharmacy training at all levels is necessary to maintain a focus on its critical role in patient care.

\section{Conflict of interest}

The authors declare no conflict of interest in this work.

\section{Disclosure statement}

This study is sponsored by International Medical University (B.Pharm.) Research Fund Budget.

\section{References}

Azer, S.A. (2015). Is Wikipedia a reliable learning resource for medical students? Evaluating respiratory topics. Advances in Physiology Education, 39(1), 5-14. https://doi.org/10.1152/ advan.00110.2014

Chang, L., Popovich, N.G., Iramaneerat, C., Smith, E.V., \& Lutfiyya, M.N. (2008). A Clinical Nutrition Course to Improve Pharmacy Students' Skills and Confidence in Counseling Patients. American Journal of Pharmaceutical Education, 72(3), 66.

https://doi.org/10.5688/aj720366

Cook, D.A., Levinson, A.J., Garside, S., Dupras, D.M., Erwin, P.J., \& Montori, V.M. (2008). Internet-based learning in the health professions: A meta-analysis. JAMA, 300(10), 1181-1196. https:// doi.org/10.1001/jama.300.10.1181

Judd, T., \& Elliott, K. (2017). Selection and Use of Online Learning Resources by First-Year Medical Students: Cross-Sectional Study. JMIR Medical Education, 3(2). https://doi.org/10.2196/mededu. 7382

Kris-Etherton, P.M., Akabas, S.R., Bales, C.W., Bistrian, B., Braun, L., Edwards, M.S., Laur, C., Lenders, C.M., Levy, M.D., Palmer, C.A., Pratt, C.A., Ray, S., Rock, C.L., Saltzman, E., Seidner, D.L., \& Van Horn, L. (2014). The need to advance nutrition education in the training of health care professionals and recommended research to evaluate implementation and effectiveness. The American Journal of Clinical Nutrition, 99(5 Suppl). https://doi.org/10.3945/ ajcn.113.073502

Macdiarmid, J.I., Gatenby, S.J., \& Mason, P.M. (1993). The pharmacist as a nutrition educator? An assessment of nutritional knowledge and undergraduate training of community pharmacists. Journal of Human Nutrition and Dietetics, 6(1), 39-47. https://doi.org/10.1111/j.1365-277X.1993.tb00346.x
Makowske, M., \& Feinman, R.D. (2005). Nutrition education: a questionnaire for assessment and teaching. Nutrition Journal, 4(1), 2. https://doi.org/10.1186/1475-2891-4-2

Manolakis, P.G., \& Skelton, J.B. (2010). Pharmacists' Contributions to Primary Care in the United States Collaborating to Address Unmet Patient Care Needs: The Emerging Role for Pharmacists to Address the Shortage of Primary Care Providers. American Journal of Pharmaceutical Education, 74(10), https:// doi.org/10.5688/aj7410s7

Munuo, A.E., Mugendi, B.W., Kisanga, O.A., \& Otieno, G.O. (2016). Nutrition knowledge, attitudes and practices among healthcare workers in management of chronic kidney diseases in selected hospitals in Dar es Salaam, Tanzania; a cross-sectional study. BMC Nutrition, 2(1), 6. https://doi.org/10.1186/ s40795-016-0045-y

O'Carroll, A.M., Westby, E.P., Dooley, J., \& Gordon, K.E. (2015). Information-Seeking Behaviors of Medical Students: A CrossSectional Web-Based Survey. JMIR Medical Education, 1(1). https://doi.org/10.2196/mededu.4267

Pearce, K.L., \& Cross, G. (2013). A 4-Week Nutrition and Therapeutics Course in an Undergraduate Pharmacy Program. American Journal of Pharmaceutical Education, 77(7), 154. https://doi.org/10.5688/ajpe777154

Pogge, E. (2013). A Team-Based Learning Course on Nutrition and Lifestyle Modification. American Journal of Pharmaceutical Education, 77(5), 103. https://doi.org/10.5688/ajpe775103

Valdez, C.A., Thompson, D., Ulrich, H., Bi, H., \& Paulsen, S. (2006). A Comparison of Pharmacy Students' Confidence and Test Performance. American Journal of Pharmaceutical Education, 70(4), 76. https://doi.org/10.5688/aj700476 